CHAPTER 10

TAI-KADAI AS A SUGBROUP OF AUSTRONESIAN ${ }^{1}$

Laurent SAGART

1614 words

IS THE AN-RELATED VOCABULARY IN TAI-KADAI DUE TO

\title{
CHANCE RESEMBLANCES?
}

Benedict (1942; 1975) argued from similarities in basic vocabulary, including personal pronouns and numerals, that Tai-Kadai and Austronesian (AN) are two distinct phyla going back to a common ancestor: Proto-Austro-Tai (PAT).

Benedict's lists of cognates contain many look-alikes and undetected Chinese loans to Tai, ${ }^{2}$ but one set of words suffices to show that at least some vocabulary is genuinely shared by Tai-Kadai and AN, not as a result of chance (Table 10.1).

Table 10. 1. A sound correspondence between Austronesian and Tai-Kadai

\begin{tabular}{lcccc}
\hline & PAN & PMP & Tai & Lakkia \\
\hline die & maCay & matay & ta: $\mathrm{i}_{1}$ & plei $_{1}$ \\
eye & maCa & mata & ta $_{1}$ & pla $_{1}$ \\
bird & & manuk & nok $_{8}$ & mlok $_{7}$ \\
\hline
\end{tabular}




\section{IS THE AN-RELATED VOCABULARY IN TAI-KADAI DUE TO BORROWINGS?}

Thurgood (1994) claimed that within Tai-Kadai, the AN-related vocabulary obeys different correspondences from the rest. ${ }^{3}$ He concluded that the AN-related vocabulary is borrowed from an early pre-AN source. However the vocabulary shared by Tai-Kadai and AN is very basic: it includes the 1sg, 2sg and 2pl personal pronouns; all the numerals above 'one'; bodypart terms like 'eye', 'tongue', 'hand'; terms for natural objects like 'moon', 'water'; verbs like 'die', etc. Borrowing such a set of vocabulary is probably not impossible, given sufficient pressure, but if so, one should also expect to find many, many loanwords in the cultural vocabulary. This is precisely where the difficulty arises: items of cultural vocabulary shared by Tai-Kadai and Austronesian are quite scarce (terms for rice cultivation, for instance, are all but missing; see Blench, this volume). It appears, then, that neither chance nor borrowing are likely explanations for the lexical comparisons between Tai-Kadai and AN. The only remaining explanation is genetic, as Benedict argued. For a realistic list of likely cognates between Austronesian and Tai-Kadai, see Ostapirat, this volume.

THE AN-RELATED VOCABULARY IN TAI-KADAI LACKS FEATURES OLDER THAN PAN

If Benedict is right that Tai-Kadai and Austronesian are coordinate taxa under Austro-Tai, then we should find in Tai-Kadai some features which are more conservative than, and throw light on, reconstructed Proto-Austronesian. 
Benedict thought that the comparisons in Table 10.1 above provided just that kind of evidence. He reconstructed the Proto-Austro-Tai words for 'die', 'eye' and 'bird' as *mapla, *maplay, *mamluk, with medial clusters ${ }^{4}$ preserved in Lakkia and Saek but simplified to -t-, -t- and -n- in Tai; the first syllable (ma- in all three cases ! a meaningless fact in his interpretation) being lost. He thought that the medial clusters -pl- and -ml- of PAT evolved to PAN -C- and -N- respectively. However, another account of the genesis of the Tai and Lakkia forms is possible. The following is based on Haudricourt (1956; here slightly modified):

'eye' mata $>$ mta $>$ pta $>$ Tai ta, Lakkia pla

'die' $\quad$ matay $>$ mtay $>$ ptay $>$ Tai tai, Lakkia plei

'bird' manuk > mnuk > Tai nok, Lakkia mlok

Haudricourt's explanation is preferable to Benedict's because it accounts for the Tai-Kadai facts without requiring any consonant clusters in the ancestral language; because it does not treat as coincidence the fact that the first syllable of the three words is ma-; and because it does not require the rather unusual sound change pl- > t- to occur independently in Austronesian and in Tai-Kadai. Haudricourt's explanation also makes stronger predictions for the Tai-Kadai data: it predicts that if an AN-related Tai-Kadai form for 'eye' or 'die' shows a cluster such as pl- or pr-, the first syllable ma- in the corresponding AN form will not be separately reflected (for instance as prenasalization), since m- in the first syllable is already reflected as Tai-Kadai p-; while in the case of a Tai-Kadai form for 'eye' 
or 'die' with a non-cluster alveolar stop initial, prenasalization is possible. This prediction is verified: e.g. Shui nda ${ }_{1}$ 'eye' (from $*$ nta $<$ mta $<$ mata), but no TaiKadai language ever shows mpl- or mpr- in either 'eye' or 'die'.

\section{THE AN-RELATED VOCABULARY IN TAI-KADAI HAS MALAYO- POLYNESIAN FEATURES}

According to many Austronesianists, PAN, the ancestor of all living AN languages, was spoken in Taiwan around 5,500 BP. It is also widely recognized that one migration out of Taiwan around 4,500 BP resulted in a language, ancestral to all living AN languages outside of Taiwan: Proto-Malayo-Polynesian (PMP). Malayo-Polynesian languages share characteristics which are regarded as innovations defining PMP. The most important of these relate to the $2^{\text {nd }}$-person pronouns (Blust 1977). According to Blust, there were two sets of personal pronouns in PAN, nominative and genitive. These two sets had the same endings for each person: thus all PAN 2sg pronouns ended in -Su, and all 2pl pronouns ended in -mu. Neither -Su nor -mu occurred at any other position in either paradigm. Evolution to PMP was complex and asymmetrical. -Su forms were maintained as 2sg pronouns but one of them: *(n)i-Su, in an unexplained change, was transferred to a plural function, becoming $2 \mathrm{pl}$ in both sets, where it competed with original -mu forms. Conversely, the PAN 2pl form in the genitive set *(n)imu became a 2sg polite form. These innovations - transfer of the 2sg (n)i-Su to 2pl and politeness shift of genitive $2 \mathrm{pl} *(\mathrm{n}) \mathrm{i}$-mu to polite $2 \mathrm{sg}$ - occur in AN languages outside of Taiwan, but not within it. 
The corresponding Tai-Kadai forms (or rather 'Proto-Kam-Tai', PKT, as reconstructed by Liang and Zhang 1996) are shown in Table 10.2.

Table 10.2: PAN $2^{\text {nd }}$-person pronoun (endings) compared with Proto-Kam-Tai

\begin{tabular}{lll}
\hline & PAN & PKT \\
\hline $2 s g$ & $-\mathrm{Su}$ & $*$ məu \\
$2 p l$ & $-\mathrm{mu}$ & $*_{\text {sou }}$ \\
& & \\
\hline
\end{tabular}

Source: Liang and Zhang (1996)

Table 10.2 shows that the Tai-Kadai $2^{\text {nd }}$-person pronouns share with PMP the transfer of a -Su form to a plural function, and the politeness shift resulting in a -mu form being used as a singular pronoun. This mismatch between PAN and Tai-Kadai $2^{\text {nd }}$-person pronouns was known to Benedict: he spoke (1975: 208) of a "flip-flop" but did not explain it. While the politeness shift affecting PAN *(n)imu 'you pl.' could well have taken place independently in Tai-Kadai and in PMP, the transfer of a -Su form to a plural function is highly idiosyncratic and can hardly have occurred twice.

Another MP feature in Tai-Kadai concerns the word for 'bird': this word, PAN *qayam, changed its meaning to 'domesticated animal' in a language ancestral to PMP and Ketagalan, a north-eastern Formosan language, and was subsequently replaced by a new form: PMP *manuk 'bird', Ketagalan manuk(ə), manukka 'bird' 
(Tsuchida, Yamada and Moriguchi 1991). Tai-Kadai, again, aligns with PMP (and Ketagalan), not PAN (see Table 10.1).

It cannot be the case, however, that the AN-related forms in Tai-Kadai originate in a MP language, because the AN vocabulary in Tai-Kadai also has some features older than PMP (though none is older than PAN): for instance, retention of a sibilant articulation for PAN *S in some words (such as the 2 pl pronoun in Table 10.2), while PMP changes *S to *h. Ostapirat (this volume) finds evidence for Tai-Kadai preservation of the PAN contrast between ${ }^{*} \mathrm{C}$ and $* t$; while PAN ${ }^{*} \mathrm{~N}$, which merges with ${ }^{*} \mathrm{n}$ in PMP, has some l- reflexes in Tai-Kadai (Proto-Kra *lak 'child' = PAN *aNak ${ }^{5}$.

\section{A NEW HYPOTHESIS}

Both Benedict and Thurgood regard Tai-Kadai as a very old phylum, with considerable diversification among daughter languages. Ostapirat (2000; this volume) depicts a more compact and relatively recent taxon, with the first split taking place no more than 4000 years ago. This makes Tai-Kadai young enough to be a subgroup, rather than a sister phylum, of Austronesian. That would help explain why Tai-Kadai shares some post-PAN innovations with certain AN languages. I will therefore hypothesize that Tai-Kadai has its origin in an early Austronesian language called here 'AAK' (Austronesian Ancestor of Tai-Kadai). AAK was a daughter language of PAN, and a close relative of PMP: it shared some innovations with PMP, but was more conservative in other respects. I 
tentatively place it within the East Coast Linkage (ECL), a primary branch of AN (see Chapter 9, figure 1). AAK left no descendants in the Austronesian world proper. In historical terms, one may suppose that AAK speakers, perhaps from Eastern Taiwan, settled the Guangdong coast. There they sustained intimate contact with a local population. As a result of this interaction, AAK was to a large extent relexified, with only the most basic elements of its vocabulary resisting. The linguistic identity of the relexifier remains an open question: that much of the Kadai vocabulary of rice cultivation is apparently of Austroasiatic (AA) origin (Ferlus, p.c.; Blench, this volume) is weakly suggestive of an early AA-related language, ${ }^{6}$ but the fact that much of the non-Austronesian and non-Chinese vocabulary in Tai-Kadai is without clear connections points in the direction of a language belonging to an extinct phylum, though conceivably one with macrophylic connections to AA or Hmong-Mien.

\section{ABBREVIATIONS}

AA Austroasiatic

AAK Austronesian ancestor of Kadai

AN Austronesian

MP Malayo-Polynesian

PAN proto-Austronesian

PKT proto-Kam-Tai

PMP proto-Malayo-Polynesian

PAT proto-Austro-Tai 


\section{REFERENCES}

Bellwood, P. (1997) Prehistory of the Indo-Malaysian archipelago, Honolulu: University of Hawai'i Press.

Benedict, P.K. (1942) 'Thai, Kadai and Indonesian: a new alignment in Southeastern Asia', American Anthropologist 44: 576-601.

— (1975) Austro-Thai: language and culture, New Haven: HRAF Press.

Blust, R. A. (1977) 'The Proto-Austronesian pronouns and Austronesian subgrouping: a preliminary report', University of Hawai'i working papers in linguistics 9, 2: 1-15.

Haudricourt, A.-G. (1956) 'De la restitution des initiales dans les langues monosyllabiques : le problème du thai commun', Bulletin de la Société de Linguistique de Paris, 52: 307-322.

Liang, M. and Zhang, J.-R. (1996) Dong-Tai Yuzu Gailun, Beijing: Zhongguo Shehui Kexue Chubanshe.

Ostapirat, W. (2000) Proto-Kra, Linguistics of the Tibeto-Burman Area 23.1.

Peiros, I. (1998) Comparative Linguistics in Southeast Asia, Canberra: Pacific Linguistics.

Sagart, L. (1999) The Roots of Old Chinese, Amsterdam: John Benjamins.

Thurgood, G. (1994) 'Tai-Kadai and Austronesian: the nature of the relationship’, Oceanic Linguistics 33, 2: 345-368. 
Tsuchida, S. Yamada, Y. and Moriguchi, T (1991) Linguistic materials of the Formosan sinicized populations I: Siraya and Basai, Tokyo: The University of Tokyo, Linguistics Department. 


\footnotetext{
${ }^{1}$ This work was supported in part by a grant from the Origine de l'homme, origine du langage, origine des langues program of the Centre National de la recherche scientifique, France.

${ }^{2}$ See for instance the discussion of metal names in Sagart (1999: 199-200).

${ }^{3}$ See Ostapirat, this volume, for a different view.

${ }^{4}$ He sometimes wrote these clusters as -pr-, -pr-, -mr-.

${ }^{5}$ Some Tai-Kadai forms reflect PAN *N as n, however: Siamese naam ${ }_{\mathrm{C}}$ 'water', PAN *daNum 'id.': but see Ostapirat (this volume).

${ }^{6}$ Peiros (1998: 229-245) draws attention to Tai-Kadai words shared with AA (mostly with Vietnamese), which are possibly loans from Austroasiatic: 'big', 'come', 'drink', 'dry', 'ear', 'full', 'green', 'long', 'moon', 'many', 'mountain', 'neck', 'new', 'one', 'speak', 'tooth', 'this', 'tongue', 'yellow', 'you' (sg).
} 